\title{
A comparative analysis of infraorbital foramen size in Paleogene euarchontans
}

\author{
Magdalena N. Muchlinski ${ }^{1}$ and E. Christopher Kirk ${ }^{2,3}$ \\ ${ }^{1}$ Center for Anatomical Sciences, University of North Texas, Health Science Center \\ ${ }^{2}$ Department of Anthropology, University of Texas at Austin \\ ${ }^{3}$ Jackson School Museum of Earth History, University of Texas at Austin \\ Corresponding Author: \\ Center for Anatomical Sciences \\ University of North Texas Health Science Center \\ 3500 Camp Bowie Blvd., RES 232C \\ Fort Worth, TX 76107, USA \\ Phone: $817-735-2037$ \\ Fax: 817-735-2126 \\ email: magdalena.muchlinski@unthsc.edu
}

Grant sponsors: National Science Foundation, Grant number: 0622422; Field Museum

Visiting Scholar Award; Philanthropic Educational Opportunity Scholarship.

Key words: Vibrissae, infraorbital foramen area, infraorbital nerve, somatosensation, mechanoreception, Primates, Plesiadapiformes, Euarchonta, Euarchontoglires 


\begin{abstract}
The size of the infraorbital foramen (IOF) is correlated with the size of the infraorbital nerve and number of mystacial vibrissae in mammals. Accordingly, IOF cross-sectional area has been used to infer both the rostral mechanoreceptive acuity and phylogenetic relationships of extinct crown primates and plesiadapiforms. Among living mammals, extant primates, scandentians, and dermopterans (Euarchonta) exhibit smaller IOF crosssectional areas than most other mammals. Here we assess whether fossil adapoids, omomyoids, and plesiadapiforms show a reduction in relative IOF area similar to that characterizing extant euarchontans. The IOFs of 12 adapoid, seven omomyoid, 15 plesiadapiform, and three fossil gliran species were measured and compared to a diverse extant mammalian sample. These data demonstrate that adapoids and omomyoids have IOFs that are similar in relative size to those of extant euarchontans. Conversely, IOFs of plesiadapiforms are on average about twice as large as those of extant euarchontans and are more comparable in size to those of extant non-euarchontan mammals. These results indicate that crown primates share a derived reduction in relative IOF size with treeshrews and colugos. Accordingly, a decreased reliance on the muzzle and an increased reliance on the hands for environmental exploration may have first evolved in the euarchontan stem lineage. However, the relatively large IOFs of plesiadapiforms imply a continued reliance on the muzzle for close exploration of objects. This finding may indicate that either parallel evolutionary decreases in IOF size occurred within Euarchonta or that plesiadapiforms lie outside the euarchontan crown group.
\end{abstract}




\section{Introduction}

Located below the inferior margin of the orbit, the mammalian infraorbital foramen (IOF) transmits the infraorbital branch of the trigeminal nerve. The infraorbital nerve mediates the general sense of touch for most of the anterior rostrum and upper lip. For decades, the size of the IOF has been used to draw inferences regarding the somatosensory abilities of the snout in fossil species (Kay and Cartmill, 1974, 1977; Gingerich and Martin, 1981; Zheng, 1984; Czaplewski, 1991; Kay et al., 1992; Simons 1987, 2001; Rasmussen and Simons, 1992; Fleagle, 1999; Brunet et al., 2002; Shigehara et al., 2002; Ni et al., 2004; Beard and Wang, 2004; Kay et al., 2004a,b; MacPhee and Horovitz, 2004; Rossie et al., 2006; Goin et al., 2007; Tabuce et al., 2009). However, the explicit relationship between IOF size, infraorbital nerve size, phylogeny, and ecology has only recently been examined using large quantitative comparative datasets. Muchlinski (2008) used dissections of 29 species from seven mammalian orders to demonstrate that IOF area is highly correlated with infraorbital nerve cross-sectional area. Muchlinski (2010a) also showed that IOF area is significantly correlated with the total number of mystacial vibrissae (whiskers) in a sample of 238 mammal species. These findings indicate that IOF area is a good osteological proxy for infraorbital nerve size that provides a quantitative basis for reconstructing rostral mechanoreceptive abilities of fossil taxa (Muchlinski et al., 2010; Kirk et al., 2014).

Functional significance of IOF area

The infraorbital nerve innervates specialized sensory end organs (mechanoreceptors) associated with the upper lip, vibrissae, and rhinarium (Patrizi and Munger, 1966; Gasser and Wise, 1971). Mechanoreceptors located in the rostral skin of 
mammals include Merkel, Ruffini, and Pacinian corpuscles (Martini and Timmons, 1997; Ebara et al., 2002). These sensory receptors variably respond to mechanical forces such as tension, pressure, and displacement. The mechanoreceptive acuity and size of the cortical representation of a region are positively correlated with receptor density (Dehnhardt and Kaminski, 1995; Catania and Kaas, 1997; Nicolelis et al., 1997). Regions with high receptor densities and high mechanoreceptive acuity require greater nerve fiber innervation (Kandel et al., 2000; Oelschlager and Oelschlager, 2002; Marino, 2007). Nerve cross-sectional area is typically a reliable measure of total axon count, as indicated by examples from the optic (Jonas et al., 1992; Cull et al., 2003) and hypoglossal (Mackinnon and Dellon, 1995) nerves. Accordingly, species with large numbers of maxillary mechanoreceptors supporting highly acute mechanoreceptive discriminatory abilities (henceforth referred to as "maxillary mechanoreceptivity") should demonstrate relatively large infraorbital nerve cross-sectional areas. Furthermore, because about 85 $95 \%$ of IOF cross-sectional area is explained by infraorbital nerve cross-sectional area (Muchlinski, 2008)1 ${ }^{1}$, species with well-developed maxillary mechanoreceptivity are also expected to possess large IOFs.

Variation in the number of mystacial vibrissae has been previously presented as one explanation for interspecific variation in IOF area among mammals (Kay and Cartmill, 1974, 1977; Martin, 1999). The specialized mechanoreceptors innervated by the infraorbital nerve are found in high densities around the vibrissa shaft (Renchan and

\footnotetext{
${ }^{1}$ A small artery, but no vein, also passes through the IOF. Nonetheless, infraorbital nerve area scales isometrically with IOF area, and thus the relative portion of the IOF devoted to blood and nerve supply remains constant (Muchlinski, 2008).
} 
Munger, 1986; Munger and Ide, 1988; Halata, 1993; Dehndardt et al., 1999; Ebara et al., 2002). Mammals with a greater number of vibrissae are therefore expected to have a higher concentration of mechanoreceptors than animals with fewer vibrissae. Although there is a significant positive correlation between IOF area and mystacial vibrissa count among mammals (Muchlinski, 2010a), variation among taxa in this relationship is sufficiently great that IOF area cannot be used to reconstruct specific numbers of mystacial vibrissae in fossil taxa. For example, anteaters and kinkajous have similar sizeadjusted IOF areas, but anteaters do not have vibrissae while kinkajous have more than one hundred vibrissae in total (Muchlinski, 2010a). Among primates, humans and the mottle-face tamarin (Saguinus inustus) have identical size-adjusted IOF areas, and yet tamarins have about 15-20 mystacial vibrissae and humans have none (Muchlinski, 2010a). Accordingly, although the number of mystacial vibrissae clearly influences IOF area, interspecific variation in IOF area is probably more closely tied to maxillary mechanoreceptivity generally rather than vibrissa number specifically (Szalay, 1981; Muchlinski, 2010a).

Interspecific variation in IOF area

Mammals demonstrate considerable interspecific variation in relative IOF area (Kay and Cartmill, 1974, 1977; Muchlinski, 2010a). The largest relative IOFs occur in some rodents, eulipotyphlans, afrosoricids, carnivorans, the honey possum (Tarsipes rostratus), and the platypus (Ornithorhynchus anatinus) (Muchlinski, 2008, 2010a; Kirk et al., 2014). By contrast, primates, scandentians (treeshrews), dermopterans (colugos), and xenarthrans are derived in possessing relatively small IOF areas compared to other mammals (Muchlinski, 2008, 2010a; Kirk et al., 2014). Because primates, scandentians, 
and dermopterans comprise a single clade (Euarchonta: Murphy et al., 2001; Kriegs et al., 2007), these data suggest that substantial decreases in IOF area and maxillary

mechanoreceptivity have occurred at least twice in the early evolution of placental mammals (i.e., in the stem lineages of both Euarchonta and Xenarthra). However, it is also possible that decreases in relative IOF area evolved more than once in euarchontan evolution.

Previous comparative research also suggests that strepsirrhine primates have larger IOFs than haplorhine primates (Kay and Cartmill, 1977). However, analyses of expanded comparative samples suggest instead that there is no significant difference in relative IOF area between living haplorhines and strepsirrhines (Muchlinski, 2008, 2010b). This finding suggests that IOF area cannot be used as evidence for the subordinal affiliation of fossil crown primates (e.g., Rasmussen and Simons, 1992). Although relative IOF area alone cannot be used to distinguish a strepsirrhine from a haplorhine, the available comparative data nevertheless suggest that IOF area may be potentially informative regarding the euarchontan affinities of fossil taxa.

\section{Goals of the present analysis}

The objective of this study is to understand better the evolution of IOF size and maxillary mechanoreceptivity within Euarchonta. To achieve this goal, we measured relative IOF area in four key groups of fossil taxa: adapoids (stem strepsirrhines), omomyoids (stem haplorhines or stem tarsiiforms), plesiadapiforms (fossil euarchontans), and fossil representatives of Glires (the sister taxon to Euarchonta; Murphy et al., 2001; Kriegs et al., 2007). These data for fossil taxa were compared with a large sample of IOF sizes in living mammals in order to determine which fossil groups share the derived 
reductions in IOF area characteristic of extant euarchontans. As noted previously, data for extant mammals suggest that substantial decreases in IOF area and maxillary mechanoreceptivity have occurred at least twice in the early evolution of placental mammals (i.e., in the stem lineages of both Euarchonta and Xenarthra; Muchlinski, 2008, 2010a; Kirk et al., 2014). Accordingly, we expect the fossil crown primates in our comparative sample (adapoids and omomyoids) to resemble living primates in exhibiting relatively small IOF sizes. Most analyses of plesiadapiform phylogenetic relationships suggest that this assemblage of Paleogene mammals lies within the euarchontan crown group (e.g., as stem primates: Bloch et al., 2007, 2016; Silcox et al., 2010; Chester et al., 2015; as stem Primatomorpha and Dermoptera: Ni et al., 2013). Accordingly, we expect plesiadapiforms to have relatively small IOF sizes, like extant euarchontans. By contrast, we expect the fossil glirans in our sample to have larger relative IOF sizes than the euarchontans in our comparative sample. These expectations reflect the most parsimonious interpretation of our comparative data (Muchlinski, 2008, 2010a). Deviations from these predictions would be consistent with the alternative possibilities that (1) the evolution of relative IOF size in Euarchontoglires was subject to homoplasy, or (2) that our understanding of the phylogenetic relationships of the fossil taxa in our analysis is incorrect.

\section{Materials and methods}

\section{Sample}

The IOF areas of museum osteological specimens from 20 extant mammalian orders were sampled for this study. Representatives from 302 mammalian species were included ( $n=1355$ specimens; Supplementary Online Material [SOM] S1), of which 73 
were primate species ( $n=298$ specimens; see Muchlinski, 2010b). In hystricomorphous and myomorphous rodents, a portion of the masseter passes through the IOF along with the infraorbital nerve and artery. The relative size of the IOF in these rodents is thus substantially larger than in other mammalian taxa and is less clearly indicative of maxillary mechanoreceptivity (Muchlinski, 2008). Accordingly, hystricomorphous and myomorphous rodents were excluded from this analysis. Fossil crown primates measured for this analysis include adapoids ( $n=12$ species) and omomyoids ( $n=7$ species). Measurements were also taken for 6 plesiadapiform families, including the Carpolestidae ( $n=2$ species), Microsyopidae ( $n=3$ species), Micromomyidae ( $n=1$ species), Palaechthonidae ( $n=1$ species), Paromomyidae $(n=3$ species $)$, and Plesiadapidae $(n=5$ species). Fossil gliran taxa measured for this analysis include the stem rodents Rhombomylus and Tribosphenomys (Meng and Wyss, 2001; Meng et al., 2003) and the stem lagomorph Dawsonolagus (Li et al., 2007). Paleogene scandentians (e.g., Ptilocercus kylin: Li and Ni, 2016) and dermopterans (e.g., Dermotherium: Marivaux et al., 2006) were not included in this analysis due to a lack of fossil specimens preserving intact IOFs. Specimen numbers and metric data used in this analysis are provided in Table 1.

\section{Measurements}

The IOFs of extant and extinct taxa were measured differently. For extant mammals, molds were created of the IOF outlet using a flexible and injectable molding material. These molds were sectioned and photographed under a stereomicroscope. From these images, IOF area (in $\mathrm{mm}^{2}$ ) was calculated using Scion Image ${ }^{\circledR}$ software (for details see Muchlinski, 2010a). For fossils, the skull or skull fragment was placed under a 
microscope, and with the IOF parallel to the lens, was photographed with a scale. IOF area was then measured using Scion Image ${ }^{\circledR}$. This method was used for fossils due to concerns that the molding material might damage delicate fossil specimens. To evaluate whether these two measurement techniques would yield adequately similar results, the IOF areas of 15 specimens were measured using both of the methods described above. A Spearman's rank correlation shows that the values obtained from the two measurement methods correlate significantly $(n=15, \mathrm{r}=0.99, p<0.0001)$ and scale isometrically (Muchlinski, 2008).

IOF area is positively correlated with body mass (Muchlinski, 2010b). Accordingly, IOF area measurements must be size-adjusted in order to compare IOF area across a wide range of body sizes. The area (maximum length $\mathrm{x}$ maximum width) of the upper second molar was chosen for IOF area size standardization. Although molar area is not a perfect surrogate for body or head size, molar area is nevertheless highly correlated with body mass and scales isometrically (Kay, 1974, 1975). Furthermore, the upper second molar may be readily measured in most fossil specimens that preserve the IOF. Analytical methods

Both conventional and phylogenetic statistical methods were used in this study. A likelihood ratio test was not performed since all $\lambda$ values were greater than 0.90 . All data analyses were performed using species mean data from Table 1 and SOM S1. Conventional statistics were run using $\mathrm{JMP}^{\circledR}$ version 12 and phylogenetically adjusted statistics were run using the R packages ape (Paradis et al., 2004), caper (Arnold et al., 2010; Orme et al., 2013; R Core Team 2013), geiger (Luke et al., 2008), nlme (Pinheiro et al., 2015), and picante (Kembel et al., 2010). The phylogenetic branching sequence 
used in these analyses follow Bininda-Emonds et al. (2005) (SOM S2 and S3). All graphs were created in $\mathrm{JMP}^{\circledR}$.

An analysis of covariance (ANCOVA) and a phylogenetic analysis of covariance (pANCOVA) were conducted to test whether extant euarchontan and non-euarchontan mammals differ in relative IOF area. In these ANCOVAs, both the predictor (molar area in $\mathrm{mm}^{2}$ ) and response (IOF area in $\mathrm{mm}^{2}$ ) variables were natural- $\log (\mathrm{ln})$ transformed. All data examined using ANCOVAs met model assumptions (e.g., regression slopes were not significantly different). Only the results for differences in y-intercept will be presented. Significance was set at $p<0.05$ for both conventional and phylogenetic ANCOVA pairwise comparisons.

To compare relative IOF sizes between taxa, residual IOF area was calculated for each species using either a GLS or a PGLS regression of $\ln$ IOF area versus $\ln$ molar area. The regression line was fit to species mean data for all extant mammals (GLS: ln $\mathrm{IOF}$ area $=-1.57+0.84 \ln$ molar area, Intercept $\mathrm{CI}=-1.39--1.75$ Slope $\mathrm{CI}=0.81-0.87$, $\mathrm{r}^{2}=0.86, p<0.0001 ;$ PGLS: In IOF area $=-1.07+0.77 \ln$ Molar area, $\mathrm{r}^{2}=0.59, p<$ 0.0001, Intercept $\mathrm{CI}=-2.19-0.05$, Slope $\mathrm{CI}=0.70-0.80, \lambda=0.99)$. Residual IOF areas obtain from a GLS and PGLS regression were then compared using a Student's t-tests. Because extant Glires (rodents and lagomorphs) have significantly larger residual IOF areas than all of the other mammalian groups in our comparative sample (Figure 2, Table 2), separate t-tests were calculated for Glires and for non-euarchontogliran mammals.

\section{Results}

Figure 1 shows a bivariate plot of $\ln$ IOF Area versus ln Molar Area. Although there is overlap between the clusters of points representing extant euarchontan and non- 
euarchontan mammal species, it is also evident that the euarchontan distribution is transposed below the non-euarchontan distribution in this plot. This finding is confirmed by ANCOVA and pANCOVA, which demonstrate a statistically significant difference in relative IOF area between extant euarchontans and non-euarchontan mammals (Table 3). Based on the differences in y-intercept between the two groups (Figure 1), living euarchontans have IOF areas that are on average $43 \%$ smaller than those of the noneuarchontan mammals in our sample.

Comparisons of relative IOF size in extant and fossil groups are presented in Figures 2 and 4 (box plots of residual IOF area - GLS and PGLS), Figure 3 (a bivariate plot of IOF Area and Molar Area), and Table 2 (conventional t-tests and phylogenetic ttests). Residual IOF areas for both omomyoids and adapoids are significantly smaller than those of extant Glires and non-euarchontogliran mammals (Figure 2; Table 2). However, both extinct crown primate groups fall mainly within the range of the extant primate distribution (Figure 3) and do not significantly differ from living euarchontans in residual IOF area (omomyoids vs. extant euarchontans: conventional $t=2.54, p=0.09$; phylogenetic $t=1.94, p=0.06$; adapoids vs. extant euarchontans: conventional $t=-0.86$, $p=0.39 ;$ phylogenetic $t=-0.95, p=0.35$ ). These results indicate that adapoids and omomyoids resemble living euarchontans in possessing IOFs that are smaller than those of most other mammals. These data further reveal that omomyoids have residual IOF areas that fall within the lower half of both the extant primate and adapoid ranges (Figure 2). Although the differences between omomyoids, adapoids, and extant euarchontans are not statistically significant (Table 2), omomyoids do have significantly smaller residual IOF areas than extant anthropoids (conventional $t=3.81, p=0.0004$; phylogenetic $t=$ 
4.73, $p=0.003$ ) and significantly larger residual IOF areas than extant tarsiers (conventional $t=-2.81, p=0.03$; phylogenetic $t=-4.75, p=0.005$ ) (Figure 4). However, omomyoids do not differ from extant strepsirrhines in residual IOF area (conventional $t=$ $0.24, p=0.81$; phylogenetic $t=0.53, p=0.60$ ) (Figure 4).

In contrast to the fossil crown primates in our sample, residual IOF areas of plesiadapiforms are significantly larger than those of extant euarchontans (conventional $t$ $=-3.06, p=0.003$; phylogenetic $t=5.06, p<0.001$; Figure 2, Table 2). On average, the IOF areas of plesiadapiforms are approximately $47 \%$ larger than extant euarchontans, omomyoids, and adapoids of comparable M2 area. Plesiadapiforms do not differ significantly from extant non-euarchontogliran mammals in residual IOF area, but they do have significantly smaller IOF areas than extant Glires (Figure 2, Table 2). These results are reflected in Figure 3, in which the majority of plesiadapiform species plot near the upper limit of the euarchontan distribution. Of the 15 plesiadapiform taxa in our sample, only the microsyopid Microsyops latidens and the plesiadapoids Nannodectes gidleyi and Plesiadapis dubius have relatively small IOFs and plot near the center of the extant euarchontan distribution (Figure 3). By contrast, the paromomyid Ignacius and the micromomyid Tinimomys have very large IOFs and fall well above the living euarchontan distribution (Figure 3). When Ignacius and Tinimomys are excluded from the sample, the remaining plesiadapiforms still have significantly larger IOF areas than extant euarchontans (conventional $t=-3.06, p=0.003$; phylogenetic $t=-3.24, p=0.005$ ).

As a group, extant glirans have the largest IOFs in our comparative sample, even with the exclusion of the myomorphous and hystricomorphous rodents (Figure 2, Table 2). Extant glirans also have significantly larger residual IOF areas than the fossil glirans 
in our sample, although this result may be partly attributable to small sample size $(n=3)$

for the fossil taxa (Table 2). Although fossil glirans do not differ significantly in residual IOF area from either non-euarchontogliran mammals or plesiadapiforms, they do have significantly larger IOFs than crown primates, treeshrews, and colugos (Figure 2, Table 2).

\section{Discussion}

Patterns of variation in infraorbital foramen size

As a group, euarchontans have a $43 \%$ reduction in relative IOF area compared to non-euarchontan mammals. These findings are similar to those documented previously by Muchlinski (2010b). One notable difference in the two studies is that in this analysis scandentians do not have relatively larger IOF areas than extant primates, while Muchlinski (2010b) found that scandentians have significantly larger IOF areas than extant primates but significantly smaller IOF areas than most other mammals. The differences between this study's findings for treeshrews and those presented by Muchlinski (2010b) are probably the result of methodological differences. Muchlinski (2010b) size-adjusted the IOF area using the geometric mean of cranial length and width. In this study, molar area was used to size-adjust IOF area. The upper molars of scandentians resemble those of many insectivores in being relatively broad and having a dilambdodont cusp pattern (Kay, 1975; Gingerich and Smith, 1984). Moreover, tupaiid treeshrews resemble talpids, erinaceids, and macroscelideans in having relatively larger molar areas than most primates (Gingerich and Smith, 1984). It is therefore perhaps not surprising that scandentians would differ in their relationship to primates depending on whether cranial size or molar area is used as the scaling variable for size adjustment. 
Nevertheless, the results of this study are concordant with those using alternative methods (Kay and Cartmill, 1977; Muchlinski, 2010b) in indicating that all euarchontans share a reduction in relative IOF area compared to most other non-euarchontan mammals.

Our data also demonstrate that two groups of Paleogene crown primates adapoids and omomyoids - resemble other crown primates and living euarchontan mammals more generally in having relatively small IOFs compared to most other mammals. These results provide strong support for the conclusion that the last common ancestor of living primates exhibited a derived reduction in IOF area and a concomitant reduction in maxillary mechanoreceptivity.

Our finding that crown primates, scandentians, and dermopterans all have relatively small IOFs compared to most other mammals provides support for the hypothesis that the last common ancestor of Euarchonta was characterized by a derived reduction in IOF size (Muchlinski, 2008, 2010b). However, our results for both plesiadapiforms and glirans suggest that the patterns of character change in Euarchonta and their close relatives may be more complex. The fact that both living and fossil glirans exhibit larger residual IOF sizes than other mammals even when myomorphous and hystricomorphous rodents are excluded suggests that IOF size may have increased in the gliran stem lineage. If so, then Euarchonta and Glires may have undergone independent changes in IOF size compared to the primitive eutherian condition, but in opposite directions. Similarly, our findings for plesiadapiforms provide additional evidence that IOF area may have been evolutionarily labile within Euarchontoglires. If plesiadapiforms are a paraphyletic assemblage of stem primates as suggested by some morphological cladistic analyses (Bloch et al., 2007, 2016; Silcox et al., 2010; Chester et al., 2015), then 
the fact that most plesiadapiforms have larger IOFs than living euarchontans could suggest that treeshrews, colugos, and crown primates evolved relatively small IOFs in parallel (Figure 5). Alternatively, IOF size might first have decreased in the euarchontan stem lineage, then increased early in the primate stem linage, and finally decreased again prior to the origin of crown primates. Similarly, high degrees of homoplasy in IOF evolution are implied by the possibility that plesiadapiforms represent a polyphyletic assemblage of stem Primatomorpha and stem Dermoptera (Ni et al., 2013). Under this phylogenetic scenario, the crown members of Primates, Dermoptera, and Scandentia would each have evolved relatively small IOF areas in parallel (Figure 5). A final possibility is that small IOF size is a synapomorphy of Euarchonta and that plesiadapiforms retain the primitive condition of large IOF size because they are not members of the euarchontan crown group (Boyer et al., 2010, see Figure 5). If Muchlinski (2010b) is correct that extant treeshrews have larger relative IOF sizes than colugos and primates, then recent genomic data providing convincing support for the existence of Primatomorpha might also imply successive decreases in relative IOF area in both the euarchontan and primatomorph stem linages (Figure 5). Although this latter scenario is the most parsimonious with regard to the evolution of IOF size, we emphasize that the phylogenetic affinities of plesiadapiforms should not be reconstructed on the basis of IOF size alone. In this context, it is worth noting that cladistic analyses favoring stem primate status for plesiadapiforms (Bloch et al., 2007, 2016; Silcox et al., 2010; Chester et al., 2015) have identified a clade comprised of the Plesiadapidae + Carpolestidae as the sister taxon to crown primates. Here we find that most plesiadapids and all carpolestids in our sample have relative IOF areas that plot either outside or at the 
upper margin of the extant euarchontan distribution (Figure 3). Nevertheless, our finding that Microsyops latidens, Nannodectes gidleyi, and Plesiadapis dubius plot within the middle of the extant euarchontan distribution in Figure 3 suggests that at least some microsyopids and plesiadapids may have independently evolved small IOFs comparable to those of living euarchontans.

\section{Implications for the evolution of maxillary mechanoreceptivity}

The documented reduction in relative IOF area among extant euarchontans suggests that most members of this clade may depend less on maxillary mechanoreception than is typically the case among mammals generally. These findings imply that crown primates, scandentians, and dermopterans have undergone a mechanoreceptive sensory reorganization. The rostrum plays an important role in environmental exploration in animals that lack manual prehensility, have poor vision, are nocturnal, or forage in low light environments (e.g., deep ocean environments: Ahl, 1986; Anjum et al., 2006). Mammals use their muzzles to orient themselves in space (Ahl, 1987; Dehnhardt and Kaminski, 1995; Crish et al., 2006), in searching for and evaluating food (Klages et al., 2002), in capturing prey (Kemble and Lewis, 1982), and in object manipulation (Reep et al., 2001). Extant primates use their muzzles to perform many of the same tasks, particularly in food evaluation and object manipulation (Kappeler, 1984; van Roosmalen, 1985; Schilling, 2000; Dominy et al., 2001; Dominy, 2004; Dominy and Duncan, 2005; Muchlinski, 2010a). However, unlike many mammals, primates have a distinctive complex of anatomical adaptations that may have taken over many of the tasks previously carried out by the muzzle (Pocock, 1914; Cartmill, 1972; Nekaris and 
Rasmussen, 2001). The most notable of these sensory and anatomical specializations are grasping hands and feet with highly sensitive apical pads (Cartmill, 1972, 1992).

It is possible that, in addition to crown primates, manual grasping and prehensility can explain IOF area reduction in scandentians and dermopterans as well. Manual prehensility has been documented for both scandentian families, Tupaiidae (e.g., Tupaia minor) and Ptilocercidae (e.g., Ptilocercus lowii). For example, Sargis (2001) observed Tupaia minor holding fruit, mealworms, and crickets in one hand, which suggested to him that scandentians may possess primitive "primate-like" manual prehensility. Moreover, the representation of the forepaw in the somatosensory cortex is enlarged in scandentians compared to most other mammals, which suggests that the forepaw is important in object manipulation tasks (Kaas, 2008). Although scandentians are by no means as adept as primates in manipulating objects, Sargis (2001) proposed that the first euarchontans may have had incipient grasping capabilities similar to those seen in scandentians, followed later by the evolution of more refined and powerful grasping abilities in primates. In addition, Gebo (2004) proposed that the evolution of grasping hands, rather than grasping hind limbs, may be a defining step in the evolution of primates. Gebo's (2004) and Sargis' (2001) hypotheses regarding the evolution of grasping and manual prehensility mirror the proposed evolution of IOF area reduction in euarchontans. As the manual prehensility of euarchontans was refined, there may have been a shift from exploring environments with the rostrum to investigating surroundings with the hands. As rostral exploration becomes less important to early euarchontans, we hypothesize that IOF area would have decreased in relative size as the number of rostral 
mechanoreceptors diminished and the cross-sectional area of the infraorbital nerve underwent a corresponding decrease in size.

Unfortunately, the manual manipulative behaviors of colugos have not been described in detail (Vandoros and Dumont, 2004), and next to nothing is known about the somatosensory cortex of these mammals (Kaas, 2008). Thus, it is difficult to assess the functional significance of IOF area and the proposed decrease in maxillary mechanoreception in dermopterans. In order to test the possibility that the origin of Euarchonta was associated with a transfer of tactile manipulative and investigative functions from the snout to the hands, it would be useful to identify the roles that maxillary mechanoreception and manual manipulation play in the feeding and foraging behaviors of colugos compared to other extant euarchontans.

Regardless of the potential implications of relatively large IOFs in plesiadapiforms for character change within Euarchonta, the results of this study suggest that plesiadapiforms depended on maxillary mechanoreception to a greater extent than crown primates, treeshrews, and colugos. Some past paleoecological interpretations of plesiadapiforms described them as forest floor predators. For instance, Kay and Cartmill $(1974,1977)$ reconstructed Palaechthon nacimienti as an insectivore that detected prey in leaf litter using smell, hearing, and vibrissae, and which probably seized prey using its anterior dentition. More recent analyses based on new fossil material suggest instead that many plesiadapiforms were predominantly arboreal (Bloch and Boyer, 2002; Sargis, 2002; Bloch et al., 2007; Sargis et al., 2007; Kirk et al., 2008; Boyer et al., 2013; Chester et al., 2015). Some plesiadapiforms such as Ignacius and Carpolestes have elongated manual proximal phalanges relative to metacarpal length, comparable to those of extant 
primates, which suggests that they were capable of grasping small diameter branches (Kirk et al., 2008; Boyer et al., 2013). Carpolestes simpsoni also has shorter claws and longer digits than other plesiadapiforms, and possesses a divergent and opposable hallux with a nail, as in crown primates (Bloch and Boyer, 2002; Bloch et al., 2007). The grasping capabilities of Carpolestes simpsoni are described as similar to those of the marsupial Caluromys, an arboreal didelphid (Bloch et al., 2007; Sargis et al., 2007). Gebo (2004) suggests that animals that resemble Caluromys would have shifted their ecology toward terminal branch feeding. Based on similarities between Carpolestes simpsoni and Caluromys, Carpolestes simpsoni is proposed to have occupied a small branch niche, similar to that proposed for the earliest crown primates (Sargis, 2002; Bloch et al., 2007; Sargis et al., 2007). However, unlike crown primates, carpolestids have relatively larger IOFs than all primates, and they lack several diagnostic cranial features associated with enhanced visual processing when compared with crown primates (Bloch and Silcox, 2006). These observations suggest that carpolestids had not undergone the same sensory reorganization proposed for crown primates, and indicate that occupying a fine branch niche cannot by itself explain the evolution of reduced IOF size (Muchlinski, 2008, 2010).

\section{Conclusions}

Living euarchontans share a derived reduction of IOF size compared to other mammals. Members of the Paleogene crown primate groups Adapoidea and Omomyoidea also have relatively small IOFs, suggesting that the last common ancestor of living primates had a reduced IOF area compared to the ancestral condition for eutherian mammals. In contrast, most plesiadapiforms have IOFs that are significantly 
larger than those of extant Euarchonta and more comparable in size to those of noneuarchontan mammals. If plesiadapiforms are crown euarchontans (Bloch et al., 2007, 2016; Silcox et al., 2010; Ni et al., 2013; Chester et al., 2015), then our findings suggest either (1) that IOF size decreased in parallel two or more times independently within Primates, Dermoptera, and Scandentia, or (2) that evolutionary reversals led to multiple changes in IOF size within the primate stem lineage (Figure 5). Living and fossil glirans also have very large IOFs compared to other mammals, suggesting that the two main clades within Euarchontoglires underwent divergent evolutionary changes in IOF size (i.e., increased IOF size in Glires and decreased IOF size in Euarchonta). Due to the strong functional relationship between IOF size and maxillary mechanoreceptivity, these data suggest that the relatively small IOF areas of non-plesiadapiform euarchontans may be associated with a transfer of exploratory and manipulative functions from the snout to the hands. If so, then the greater reliance on the hands for manipulating objects that has been observed in living primates and some scandentians may be a feature that appeared relatively early in euarchontan evolution.

\section{Acknowledgements}

The authors would like to thank Doug Boyer, Erik Seiffert, Walter Joyce, Adam Gordon, Liza Shapiro, Nate Dominy, Robert Sussman, Suzanne Strait, and Rebecca Lewis for comments on earlier drafts, access to specimens, and with project development. MNM would also like to thank all the museums and their curators and supporting staff for access to the paleontological collections. Specifically, Bob Martin and Bruch Patterson (Field Museum of Natural History); Linda Gordon, Richard Thorington, Dave Schmidt, 
Jeremy Jacobs, Robert Purdy, and Kay Behrensmeyer (National Museum of Natural History); Jean Spence, Richard Monk, Susan Bell, Jin Meng, and Judith Galkin (American Museum of Natural History); Amy Henrici, Chris Beard, and John Wible (Carnegie Museum of Natural History); Walter Joyce, from the Peabody Museum of Natural History; Mara Johnsen and Bill Amaral (Harvard Museum of Comparative Zoology); Gregg Gunnell and Philip Gingerich (Museum of Paleontology at the University of Michigan); Timothy Rowe and Lyndon Murray (Vertebrate Paleontology Laboratory at the University of Texas at Austin); Rob Kruszynski (British Museum of Natural History); Ray Symonds (University Museum of Zoology, Cambridge); Arne Ziems (Naturhistorisches Museum Basel); Marc Godinot, Pascal Tassy, Claire Sagne

(Museum National D' Histoire Nautrelle). This project was funded by a National Science Foundation DIG: 0622422; a Field Museum of Natural History visiting scholarship; a Philanthropic Educational Opportunity Fellowship; and MU-ADVANCE.

\section{References}

Ahl, A.S., 1986. The role of vibrissae in behavior: A status review. Vet. Res. Comm. 10, 245-268.

Ahl, A.S., 1987. Relationship of vibrissal length and habits in the Siuridae. J. Mammal. $68,848-853$.

Anjum, F., Hendrik, T., Mulder, P.G., van der Burg, J., Brecht, M., 2006. Tactile guidance of prey capture in Etruscan shrews. Proc. Natl. Acad. Sci. 103, 16544-16549. 
Arnold, C., Matthews, L.J., Nunn, C.L., 2010. The 10kTrees website: a new online resource for primate phylogeny. Evol. Anthropol. 19, 114-118.

Beard, C.K., Wang, J., 2004. The eosimiid primates of the Heti formation, Yuanqu Basin, Shanxi and Henan provinces, People's Republic of China. J. Hum. Evol. 46, 401-432.

Bininda-Emonds, O.R.P., Beck, R.M.D., Purvis, A., 2005. Getting to the roots of matrix representation. Syst. Biol. 54, 668-672.

Bloch, J.I, Boyer, D.M., 2002. Grasping primate origins. Science 298, 1606-1610.

Bloch, J.I., Silcox, M.T., Boyer, D.M., Sargis, E., 2007. New Paleocene skeletons and the relationship of plesiadapiforms to crown-clade primates. Proc. Natl. Acad. Sci. 104, 1159-1164.

Bloch, J.I., Chester, S.G.B., Silcox, M.T., 2016. Cranial anatomy of Paleogene Micromomyidae and implications for early primate evolution. J. Hum. Evol. $96,58-81$.

Boyer, D.M., Prasad, G.V.R., Krause, D.W., Godinot, M., Goswami, A., Verma, O., Flynn, J.J. 2010. New postcrania of Deccanolestes from the Late Cretaceous of India and their bearing on the evolutionary and biogeographic history of euarchontan mammals. Naturwissenschaften 97, 365-377.

Boyer, D.M., Yapuncich G.S., Chester S.G.B., Bloch J.I., Godinot M., 2013. Hands of early primates. Am. J. Phys. Anthropol. 57, 33-78. 
Brunet, M., Guy, F., Pilbeam, D., Mackaye, H., Likius, A., Ahounta, D., Beauvilain, A., Blondel, C., Bocherens, H., Boisserie, J., De Bonis, L., Coppens, Y., Dejax, J., Denys, C., Duringer, P., Eisenmann, V., Fanone, G., Fronty, P., Geraads, D., Lehmann, T., Lihoreau, F., Louchart, P., Mahamat, A., Merceron, G., Mouchelin, G., Otero, O., Campomanes, P., Ponce De Leon, M., Rage, J., Sapanet, M., $\quad$ Schuster, M., Sudre, J., Tassy, P., Valentin, X., Vignaud, P., Viriot, L., Zazzo, A., Zollikofer, C., 2002. A new hominid from the upper Miocene of Chad, central Africa. Nature 418, 145-151.

Cartmill, M., 1972. Arboreal adaptations and the origin of the order primates. In: Tuttle, R. (Ed.), The Functional and Evolutionary Biology of Primates. Aldine \& Atherton, Inc., Chicago, pp. 97-122.

Cartmill, M., 1992. New views on primate origins. Evol. Anthropol. 1, 105-111.

Catania, K., Kaas, J., 1997. Somatosensory fovea in the star-nosed mole: behavioral use of the star in relations to innervation patterns and cortical representation. J. Comp. Neurol. 387, 215-233.

Chester, S.G.B., Bloch, J.I., Boyer, D.M., Clemens, W.A., 2015. Oldest known euarchontan tarsals and affinities of Paleocene Purgatorius to Primates. PNAS 112, 1487-1492.

Crish, S.D., Dengler-Crish, C., Comer, C.M., 2006. Population coding strategies and involvement of the superior colliculus in the tactile orienting behavior of naked mole-rats. Neurosci. 139,1461-1466.

Cull, G., Cioffi, G., Dong, J., Homer, L., Wang, L., 2003. Estimating normal optic nerve axon numbers in non-human primate eyes. J. Glaucoma 12, 301-306. 
Czaplewski, N., 1991. Miocene bats from the lower Valentine formation of northeastern Nebraska. J. Mammal. 72, 715-722.

Dehnhardt, G., Kaminski, A., 1995. Sensitivity of the mystacial vibrissae of harbour seals (Phoca vitulina) for size differences of actively touched objects. J. Exp. Biol. 198, 2317-2323.

Denhardt, G., Hyvärinen, H., Palviainen, A., Klauer, G., 1999. Structure and innervation of the vibrissal follicle-sinus complex in the Australian water rat, Hydromys chrysogaster. J. Comp. Neurol. 411, 550-562.

Dominy, N.J., 2004. Fruits, fingers, and fermentation: The sensory cues available to foraging primates. Integr. Comp. Bio. 44, 29-37.

Dominy, N.J., Duncan, B.W., 2005. Seed-spitting primates and the conservation and dispersion of large-seeded trees. Int. J. Primatol. 26, 631-649.

Dominy, N.J., Lucas, P.W., Osorio, D., Yamashita, N., 2001. The sensory ecology of primate food perception. Evol. Anthropol. 10, 171-186.

Kandel, E., Schwartz, J., Jessell, T., 2000. Principles of Neural Science. 4th ed. McGraw-Hill, New York..

Ebara, S., Kumamoto, K., Matsuura, T., Mazurkiewicz, J., Rice, F., 2002. Similarities and differences in the innervation of mystacial vibrissal follicle-sinus complexes in the rat and cat, a confocal microscopic study. J. Comp. Neurol. 449, 103-119.

Fleagle, J., 1999. Primate Adaptation and Evolution. Academic Press, San Diego.

Gasser, R., Wise, D.M., 1971. The trigeminal nerve in the baboon. Anat. Rec. 172, 511522. 
Gebo, D.L., 2004. Adapiformes: Phylogeny and adaptation. In: Hartwig, W.C. (Ed), The Primate Fossil Record. Cambridge University Press, Cambridge , pp. 21-44.

Gingerich, P., Smith, H.B., 1984. Allometric scaling in the dentition of primates and insectivores. In: Junger, W.L. (Ed), Size and Scaling in Primate Biology. Plenum Publishing Corporation, New York, pp. 257-272.

Gingerich, P.D., Martin, R.D., 1981. Cranial morphology and adaptations in Eocene adapidae II. The Cambridge skull of Adapis parisiensis. Am. J. Phys. Anthropol. 56, 235-257.

Goin, F., Sànchez-Villagra, M., Abello, A., Kay, R.F., 2007. A new generalized paucituberculatan marsupial from the Oligocene of Bolivia and the origin of "shrew-like" opossums. Palaeontol. 50, 1267-1276.

Halata, Z., 1993. Sensory innervation of the hairy skin (light-and electronmicroscopic study). J. Invest. Dermatol. 101, 75S-81S.

Jonas, J., Schmidt, A., Müller-Bergh, J., Schlötzer-Schrehardt, U., Naumann, O., 1992. Human optic nerve fiber count and optic disc size. Invest. Ophth.Vis. Sci. 332012-2018.

Kaas, J., 2008. The evolution of the complex sensory and motor systems of the human brain. Brain. Res. Bull. 75, 384-390.

Kappeler, M., 1984. The gibbon in Java. In: Preuschoft, H., Chivers, D., Brockelman, D. (Eds), The Lesser Apes: Evolutionary and Behavioural Biology. Edinburgh University Press, Edinburgh, pp. 19-31.

Kay, R.F., 1974. Mastication, molar tooth structure, and diet in primates. Ph.D. Dissertation, Yale University. 
Kay, R.F., 1975. The functional adaptations of primate molar teeth. Am. J. Phys. Anthropol. 43, 195-216.

Kay, R.F., Campbell, V.M., Rossie, J.B., Colbert, M.W., Rowe, T.B., 2004a. Olfactory fossa of Tremacebus harringtoni (Platyrrhini, Early Miocene, Sacanana, Argentina): Implications for activity pattern. Anat. Rec. 281A, 1157-1172.

Kay, R.F., Cartmill, M., 1974. Skull of Palaechthon nacimienti. Nature, 252, 37-38

Kay, R.F., Cartmill, M., 1977. Cranial morphology and adaptations of Palachthon nacimieni and other Paromomyidae (Plesiadapoidea, ?Primates), with a description of a new genus and species. J. Hum. Evol. 197, 19-53.

Kay, R.F., Schmitt, D., Vinyard, C., Perry, J., Shigehara, N., Takai, M., Egi, N., 2004b. The paleobiology of Amphipithecidae, South Asian late Eocene primates. J. Hum. Evol. 46, 3-25.

Kay, R.F., Thewissen, J.G.M., Yoder, A., 1992. Cranial anatomy of Ignacius graybullianus and the affinities of the Plesiadapiformes. Am. J. Phys. Anthropol. 89, 477-498.

Kembel, S.W., Cowan, P.D., Helmus, M.R., Cornwell, W.K., Morlon, H., Ackerly, D.D., Blomberg, S.P., Webb, C.O., 2010. Picante: R tools for integrating phylogenies and ecology. Bioinformatics, 26, 1463-1464.

Kemble, E., Lewis, C., 1982. Effects of vibrissal amputation on cricket predation in northern grasshopper mice (Onychomys leucongaster). Bull. Psychonomic Soc. 20, 275-276. 
Kirk, E.C., Hoffman, S., Kemp, A.D., Krause, D.W., O'Connor, P.M., 2014. Sensory anatomy and sensory ecology of Vintana sertichi (Mammalia, Gondwanatheria) from the late Cretaceous of Madagascar. J. Vert. Paleontol. 34, 203-222.

Kirk, E., Lemelin, P., Hamrick, M., Boyer, D., Bloch, J., 2008. Intrinsic hand proportions of euarchontans and other mammals: Implications for the locomotor behavior of plesiadapiforms. J. Hum. Evol. 5, 278-299.

Klages, M., Muyakshin, S., Soltwedel, T., Arntz, W.E., 2002. Mechanoreception, a possible mechanism for food fall detection in deep-sea scavengers. DeepSea Res. 49, 143-155.

Kriegs, J.O., Churakov, G., Jurka, J., Brosius, J., Schmitz, J., 2007. Evolutionary history of 7SL RNA-derived SINEs in Supraprimates. Trends Genet. 23, 158-161.

Li, C., Meng, J., Wang, Y., 2007. Dawsonolagus antiquus, a primative lagomorph from the Eocene Arshanto formation, Nei Mongol, China. Bull. Carnegie Mus. Nat. Hist.39, 1-234.

Li, Q., Ni, X. (2016) An early Oligocene fossil demonstrates treeshrews are slowly evolving "living fossils." Sci. Rep. 18627, 1-8.

Luke, J.H., Weir, J.T., Brock, C.D., Glor, R.E., Challenger, W., 2008. GEIGER: investigating evolutionary radiations. Bioinformatics 24, 129-31.

Mackinnon, S., Dellon, A., 1995. Fascicular patterns of the hypoglossal nerve. J.Reconstr. Microsurg. 11,195-198. 
MacPhee, R., Horovitz, I., 2004. New craniodental remains of the quaternary Jamaican monkey Xenothrix mcgregori (Xenotrichini, Callicebinae, Pitheciidae), with a reconsideration of the Aotus hypothesis. Am. Mus. Novit. 3434, 1-51.

Marino, L., 2007. Cetacean brains: How aquatic are they? Anat. Rec. 290, 694-700. Marivaux, L., Bobcat, L., Chaimanee, Y., Jaeger, J.J., Marandat, B., Srisuk, P., Tafforeau, P., Yamee, C., Welcomme, J.L., 2006 Cynocephalid dermopterans from the Palaeogene of South Asia (Thailand, Myanmar and Pakistan): systematic, evolutionary and palaeobiogeographic implications. Zool. Scr. 35, 395-420.

Martin, O.Y., 1999. The mystacial vibrissae: Morphological, functional, systematic and ecological aspects. M.A. Thesis, University of Zurich.

Martini, F., Timmons, M., 1997. Human Anatomy. Prentice Hall, New Jersey. Mason, V.C., Li, G., Minx, P., Schmitz, J., Churakov, G., Doronina, L., Melin, A.D., Dominy, N.J., Lim, N.T.-L., Springer, M.S., Wilson, R.K., Warren, W.C., Helgen, K.M., Murphy, W.J., 2016. Genomic analysis reveals hidden biodiversity within colugos, the sister group to primates. Sci. Adv. 2:e1600633.

Meng, J., Hu, Y., Li, C., 2003. The osteology of Rhombomylus (Mammalia, Glires): implications for phylogeny and evolution of Glires. Bull. Am. Mus. Nat. Hist. 275, 1-247.

Meng, J., Wyss, A.R., 2001. The morphology of Tribosphenomys (Rodentiaformes, Mammalia): phylogenetic implications for basal Glires. J. Mamm. Evol.8,171. 
Muchlinski M,.N., Godfrey, L.R., Muldoon, K.M., Tongasoa, L., 2010. Evidence for dietary niche separation based on infraorbital foramen size variation among subfossil lemurs. Int. J. Primatol. 81, 330-345.

Muchlinski, M.N., 2008. The infraorbital foramen, infraorbital nerve, and maxillary mechanoreception: Implications of interpreting the paleoecology of fossil mammals based on infraorbital foramen size. Anat. Rec. 291, 1221-1226.

Muchlinski, M.N. 2010a. A comparative analysis of vibrissa count and infraorbital foramen area in primates and other mammals. J. Hum. Evol. 58, 447-473.

Muchlinski, M.N., 2010b. Ecological correlates of infraorbital foramen size in primates. Am. J. Phys. Anthropol. 141, 131-141.

Munger, B., Ide, C., 1988. The structure and function of cutaneous sensory receptors. Arch. Histol. Cytol. 51, 1-34.

Murphy, W.J., Eizirik, E., Johnson, W.E., Zhang, Y.P., Ryder, A.O., O'Brien, S.J., 2001. Molecular phylogenetics and the origins of placental mammals. Nature 409, 614-618.

Nekaris, K., Rasmussen, D.T., 2001. Diet and feeding behavior of Mysore slender lorises. Int. J. Primatol. 24, 33-46.

Ni, X., Wang, Y., Hu, Y., Li, C., 2004. A euprimate skull from the early Eocene of China. Nature 427, 65-68.

Ni, X., Gebo, D.L., Dagosto, M., Meng, J., Tafforeau, P., Flynn, J.J., Beard, K.C. 2013. The oldest known primate skeleton and early haplorhine evolution. Nature. 498, 60-64. 
Nicolelis, M.A., Lin, R.C., Chapin, J., 1997. Neonatal whisker removal reduces the discrimination of tactile stimuli by thalamic ensembles in adult rats. J. Neurophysiol. 78,1691-1706.

Oelschlager, H., Oelschlager, J., 2002. Encyclopedia of Marine Mammals. Academic Press, San Diego.

Orme, C.D.L., Freckleton, R.P., Thomas, G.H., Petzoldt, T., Fritz, S.A., 2012. Caper: comparative analyses of phylogenetics and evolution in R. MethodsEcol Evol. 3, 145-151.

Paradis, E., Claude, J., Strimmer, K., 2004. APE: Analyses of phylogenetics and evolution in R language. Bioinformatics 20, 289-290.

Patrizi, G., Munger, B., 1966. The ultrastructure and innervation of rat vibrissae. J. Comp. Neurol.126, 423-436.

Pinheiro, J., Bates, D., DebRoy, S., Sarkar, D., 2015. R Core Team. nlme: Linear and nonlinear mixed effects models. R package version 3.1-128. 2015.

Pocock, R., 1914. On the facial vibrissae of mammalia. Proc. Zool. Soc. Lond. 1914, 889-912.

R Core Team, 2013. R: A Language and Environment for Statistical Computing. R Foundation for Statistical Computing, Vienna, Austria.

Rasmussen, D.T., Simons, E.L., 1992. Paleobiology of the Oligopithecines, the earliest known anthropoid primates. Int. J. Primatol. 13, 477-508.

Reep, R., Stoll, M., Marshall, C., Homer, B., Samuelson, D., 2001. Microanatomy of facial vibrissae in the Florida manatee: The basis for specialized sensory function and oripulation. Behav. Brain. Res. 58, 1-14. 
Renehan, W., Munger, B., 1986. Degeneration and regeneration of peripheral nerve in the rat trigeminal system. I. Identification and characterization of the multiple afferent innervation of the mystacial vibrissae. J. Comp. Neurol. 246,129145.

Rossie, J., Ni, X., Beard, K., 2006. Cranial remains of an Eocene tarsier. Proc. Natl. Acad. Sci. 103, 4381-4385.

Sargis, E.J., 2001. The grasping behaviour, locomotion and substrate use of the tree shrews Tupaia minor and T. tana (Mammalia, Scandentia). J. Zool. Lond. $253,485-490$.

Sargis, E.J., 2002. Primate origins nailed. Science 298, 1564-1565.

Sargis, E.J., Boyer, D.M., Bloch, J.I., Silcox, M.T., 2007. Evolution of pedal grasping in Primates. J. Hum. Evol. 53, 103-107.

Schilling, A., 2000. Organes des sens et communication chex le microcebe. Primatologie $3,85-143$.

Shigehara, N., Takai, M., Kay, R.F., Ko Aung, A., Soe, A., Tun, S., Tsubanato, T., Thein, T., 2002. The upper dentition and face of Pondaungia cotteri from central Myanmar. J. Hum. Evol. 43, 143-166.

Silcox, M.T., A.E. Benham, J.I. Bloch. 2010. Endocasts of Microsyops (Microsyopidae, Primates) and the evolution of the brain in primitive primates. J.Hum. Evol. $58,505-521$.

Simons, E.L., 1987. New faces of Aegyptopithecus from the Oligocene of Egypt. J. Hum. Evol. 16, 273-289. 
Simons, E.L., 2001. The cranium of Parapithecus grangeri, an Egyptian Oligocene anthropoidean primate. Proc. Natl. Acad. Sci. 98, 7892-7897.

Szalay, F.S., 1981. Phylogeny and the problem of adaptive significance: The case of the earliest primates. Folia Primatol. 36, 157-182.

Tabuce, R., Marivaux, L., Lebrun, R., Adaci, M., Bensalah, M., Fabre, P.H., Fara, E., Rodrigues, H.G., Hautier, L., Jaeger, J.J., Lazzari, V., Mebrouk, F., Peigne, S., Sudre, J., Tafforeau, P., Walentin, X., Mahboubi, M., 2009. Anthropoid versus strepsirhine status of the African Eocene primates Algeripithecus and Azibus: Caniodental evidence. Proc. Natl. Acad. Sci. 276, 4087-4094.

van Roosmalen, M., 1985. Subcategorizing foods in primates. In: Chivers D.J., Wood, B.A. (Eds.), Food Acquisition and Processing in Primates. Plenum Press, New York, pp. 167-176.

Vandoros, J.D., Dumont, E.R., 2004. Use of the wings in manipulative and suspensory behaviors during feeding by frugivorous bats. J. Exp. Biol. 301A, 361-366. Zheng, S., 1984. A revision of the fossil cricetines (Rodentia, Mammalia) from Zhoukoudian, the Peking Man site. Vertebrate Palasiatica 22, 179-197. 


\section{Figures}

Figure 1. A scatter plot of $\ln$ IOF area versus $\ln$ molar area for all extant mammals sampled, including scandentians $(\mathrm{S})$, dermopterans $(\mathrm{D})$, primates $(\mathrm{P})$, glirans $(\mathrm{G})$, and non-euarchontan mammals $(\mathbf{O})$. Conventional and phylogenetic ANCOVAs indicate that euarchontans have significantly smaller infraorbital foramina than non-euarchontan mammals (see Table 3 for regression parameters and test statistics). A GLS regression line was fit to extant non-euarchontans (thin solid line) and extant euarchontans (thick solid line). A pGLS regression line to extant non-euarchontans (thin dashed line) and extant euarchontans (thick dashed line).

Figure 2. Box and whisker plots illustrating differences in relative IOF area among the mammalian groups examined in this study. Only statistical significance between plesiadapiforms and euarchontans are denoted in this image. Residual IOF areas were calculated using a generalized least squares regression (A) and a phylogenetic generalized least squares regression (B) line of $\ln$ IOF area on $\ln$ molar area. The regressions were fit to all extant mammalian taxa sampled. Student's t-tests comparing residual values for groups (see Table 2) indicate that IOFs of plesiadapiforms are significantly larger than those of euarchontans and significantly smaller than those of glirans (see Table 2 - extant glirans had larger relative IOF area values than all groups sampled). Plesiadapiforms did not differ significantly from non-euarchontogliran mammals. $*=p \leq 0.05, * *=p \leq 0.01$, and $* * * *=p \leq 0.0001$ 
Figure 3. (A) Scatterplot of $\ln I O F$ area versus $\ln$ molar area for all species mean values. Convex polygons were fit around species means for extant non-euarchontan mammals (dashed polygon) and for euarchontans (solid black line polygon). All extant mammals are indicated by the pale gray symbols [scandentians (S), dermopterans (D), primates (P), glirans $(\mathrm{G})$, and non-euarchontan mammals $(\bullet)$ ]. Fossil specimens are colored black [plesiadapiforms (*); omomyoids (O); adapoids (A); non-euarchontan fossil taxa ( $\square$ ) ]. (B) Enlarged image of the euarchontan polygon shown in 3A. All adapoids and all but one omomyoid fall within the extant euarchontan polygon. Absarokius noctivagus is the only omomyoid that fell slightly below the primate distribution. The majority of plesiadapiforms and all of the extinct non-euarchontan fossil taxa ( $\square$ ) fall outside or at the upper limit of the extant euarchontan distribution. Omomyoid abbreviations: $\mathrm{An}=$ Absarokius noctivagus, $\mathrm{M}=$ Microchoerus $\mathrm{sp} ., \mathrm{Na}=$ Necrolemur antiquus, $\mathrm{Rv}=$ Rooneyia viejaensis, $\mathrm{Sc}=$ Shoshonius cooperi, $\mathrm{Th}=$ Tetonius homunculus. Adapoid abbreviations: $\mathrm{Ap}=$ Adapis parisiensis, $\mathrm{Cl}=$ Caenopithecus lemuroides, $\mathrm{Ca}=$ Cantius abditus, $\mathrm{C}=$ Cantius nuniensis, $\mathrm{Cr}=$ Cantius ralstoni, $\mathrm{Ct}=$ Cantius trigonodus, $\mathrm{Lm}=$ Leptadapis magnus, $\mathrm{Ms}=$ Mahgarita stevensi, $\mathrm{Nt}=$ Notharctus tenebrosus, $\mathrm{Nv}=$ Notharctus venticolus, $\mathrm{Pg}=$ Pronycticebus gaudryi, $\mathrm{Ph}=$ Periconodon huerzeleri, $\mathrm{Sc}=$ Smilodectes gracilis. Plesiadapiform abbreviations: $\mathrm{Cd}=$ Carpolestes dubius, $\mathrm{Cn}=$ Carpolestes nigridens, $\mathrm{Ig}=$ Ignacius graybullianus, $\mathrm{Mega}=$ Megadelphus lundeliusi, $\mathrm{Ng}$ $=$ Nannodectes gidleyi, $\mathrm{Ml}=$ Microsyops latidens, Micro $=$ Microsyops $\mathrm{sp} ., \mathrm{Pa}=$ Palaechthon alticuspus, $\mathrm{Pm}=$ Paromomys maturus, $\mathrm{Pp}=$ Phenacolemur pagei, $\mathrm{Pc}=$ Plesiadapis churchilli, $\mathrm{Pd}=$ Plesiadapis dubius, $\mathrm{Pf}=$ Plesiadapis fodinatus, $\mathrm{Pt}=$ 
Plesiadapis tricuspidens, Ts = Tinimomys tribos, Fossil non-euarchontan abbreviations:

$\mathrm{Da}=$ Dawsonolagus antiquus, $\mathrm{Rs}=$ Rhombomylus $\mathrm{sp} ., \mathrm{Tm}=$ Tribosphenomys minutus.

Figure 4. Box and whisker plots illustrating the variation in relative IOF area among omomyoids and living tarsiers, strepsirrhines, and anthropoids. Residuals were calculated as for Fig. 3. Figure A values were derived using conventional statistics while Figure B values were derived using values that took phylogeny into consideration. A Student's ttest indicates that omomyoids have significantly larger IOF residuals than living tarsiers, but significantly smaller foramina than living anthropoids. There were no significant differences between omomyoids and living strepsirrhines. $*=p \leq 0.05, * *=p \leq 0.01$, and $* * *=p \leq 0.0001$. 
Figure 5. Possible scenarios for the evolution of decreased IOF size in Euarchonta. The arrows indicated hypothetical decreases in IOF area. Top: Cladogram follows Bloch et al. (2016), in which plesiadapiforms are a paraphyletic assemblage of stem primates.

According to this scenario, IOF size could have decreased independently in "sundatheres" and crown primates, although recent genomic evidence now falsifies this topology for extant euarchontan clades and convincingly favors the existence of Primatomorpha (Mason, et al., 2016). Middle: Cladogram follows Ni et al. (2013), in which plesiadapiforms are a polyphyletic assemblage of stem primatomorphs and stem dermopterans. According to this scenario, IOF size may have decreased in crown primates, scandentians, and dermopterans independently. Bottom: Hypothetical cladogram in which plesiadapiforms are outside the euarchontan crown group. Tree topology for extant clades follows Mason et al. (2015). According to this scenario, IOF size may have decreased in both the euarchontan and primatomorph stem lineages. 


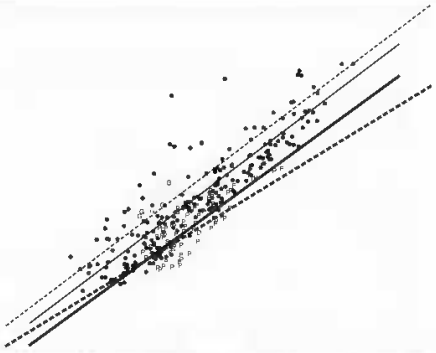



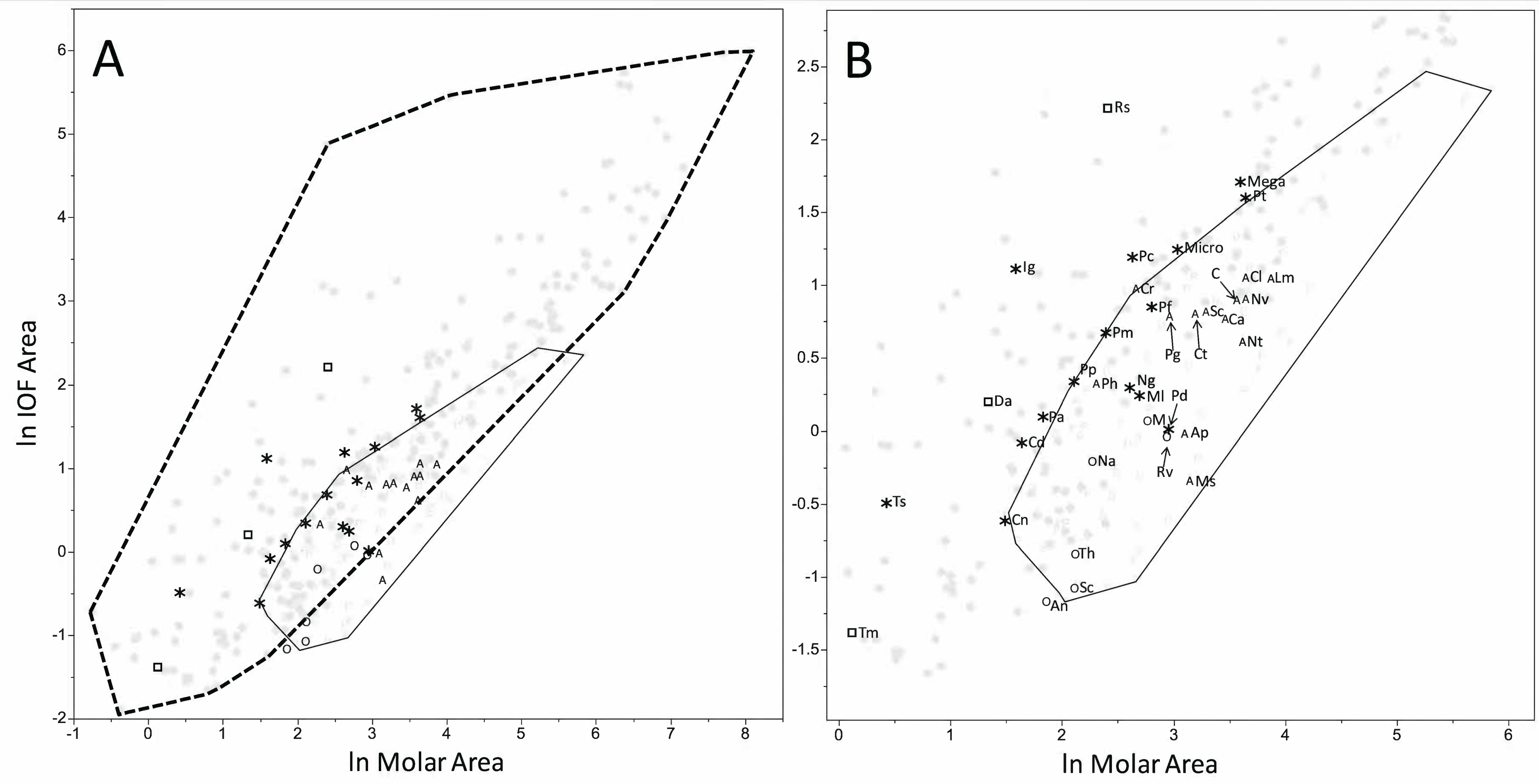
Table 1. Infraorbital foramen (IOF) area and upper second molar area (MA) measurements $\left(\mathrm{mm}^{2}\right)$ for each fossil specimen sampled.

Museum Specimen ID

IOF Area MA

\section{Adapoidea}

\section{Adapinae}

Adapis parisiensis

\begin{tabular}{|c|c|c|c|}
\hline NMB & Q I4 & 1.09 & 20.93 \\
\hline NMB & QD 102a & 0.94 & 19.01 \\
\hline NMB & QD 400 & 0.93 & 19.44 \\
\hline NMB & QD 57 & 1.15 & 23.7 \\
\hline NMB & QD 84 & 0.75 & 21.51 \\
\hline NMB & QW 2 & 0.65 & 16.36 \\
\hline NMB & QW 3 & 0.71 & 14.06 \\
\hline BMNH & M 1345 & 0.95 & 19.66 \\
\hline BNNH & M 1633 & 0.88 & 17.84 \\
\hline CMZ & M 538 & 1.18 & 23.17 \\
\hline MNHN & MaPhQ 339 & 0.81 & 26.61 \\
\hline MNHN & MaPhQ 344 & 0.66 & 23.31 \\
\hline MNHN & Montaunban 6 & 1 & 22.84 \\
\hline MNHN & PLV 14 & 0.92 & 22.9 \\
\hline MNHN & QU 11064 & 0.74 & 17.22 \\
\hline MNHN & ROS 1218 & 1.11 & 20.94 \\
\hline MNHN & QU 10884 & 2.17 & 49.68 \\
\hline NMB & QD 1 & 2.46 & 46.12 \\
\hline NMB & QD 13 & 2.56 & 44.61 \\
\hline NMB & QD 5 & 2.48 & 32.18 \\
\hline NMB & SFH 1634 & 2.35 & 56.67 \\
\hline BMNH & M 4669 & 2.38 & 52.34 \\
\hline BMNH & M 7504 & 2.33 & 56 \\
\hline MNHN & QU 10881 & 2.54 & 51.05 \\
\hline MNHN & QU 10943 & 2.65 & 39.32 \\
\hline MNHN & QU 11072 & 2.95 & 15.52 \\
\hline
\end{tabular}

Leptadapis magnus

QU 11072 


$\begin{array}{llll}\text { MNHN } & \text { QU 16692 } & 2.61 & 53.12 \\ \text { MNHN } & \text { QU 1903-20 } & 2.53 & 56.6 \\ \text { MNHN } & \text { QU 11002 } & 2.17 & 54.69 \\ \text { YPM } & \text { PU 11481 } & 2.84 & 48.28 \\ \text { MNHN } & \text { MaPhQ 210 } & 3.12 & 66.86 \\ \text { MNHN } & \text { MaPhQ 219 } & 2.33 & 49.42 \\ \text { MNHN } & \text { QU 10870 } & 4.43 & 50.23 \\ \text { MNHN } & \text { QU 10872 } & 5.6 & 47.65\end{array}$

\section{Notharctinae}

Cantius abditus

UM

93938

1.15

32.08

Cantius nunienus

AMNH 55157

2.45

35.56

Cantius ralstoni

AMNH 16094

2.65

14.4

Cantius trigonodus

YPM PU 14515

2.23

24.49

Notharctus tenebrosus

AMNH 108362

2.37

34.7

YPM 12956

1.25

37.38

USNM 1365

1.82

44.15

USNM 21864

2.12

40.93

USNM 21932

2.3

30.34

USNM 22013

1.89

36.76

USNM 23218

1.83

35.86

USNM 23277

1.73

38.07

USNM 7765

1.6

39.23

YPM 12906

1.47

37.31

CM 46507

2.12

33.29

CM 60497

2.12

32.15

CM

9411

3.16

50.18

Smilodectes gracilis

$\begin{array}{ll}\text { USNM } & 16786 \\ \text { USNM } & 21950 \\ \text { USNM } & 24892 \\ \text { USNM } & 363764 \\ \text { USNM } & 17994\end{array}$

1.99

24.92

2.73

28.08

1.74

29.66

1.68

29.37

2

24.06 


$\begin{array}{llll}\text { UM } & 100000 & 3.47 & 26.93 \\ \text { UM } & 101231 & 2.23 & 25.86\end{array}$

\section{Cercamoniinae}

$\begin{array}{llll}\text { Caenopithecus lemuroides } & \text { NMB } & \text { EF } 382 & 2.86\end{array}$

$\begin{array}{lllll}\text { Mahgarita stevensi } & \text { TMM } & 41578-9 & 0.71 & 23.32\end{array}$

$\begin{array}{llll}\text { Periconodon huerzeleri } & \text { NMB } & \text { BHS 222 } & 1.38\end{array}$

$\begin{array}{llll}\text { Pronycticebus gaudryi } & \text { MNHN } & \text { QU, no number } & 2.18\end{array}$

$\begin{array}{llll}\text { MNHN } & \text { QU } 11056 & 2.2 & 19.43\end{array}$

\section{Omomyoidea}

Microchoerinae

Microchoerus sp.

Necrolemur antiquus

MNHN Montpellier, no number 1.07

15.97

$\begin{array}{llll}\text { MNHN } & \text { QU } 11059 & 0.56 & 10.63\end{array}$

NMB

QH 468

1.19

11.16

Necrolemur antiquus

NMB QW 625

0.36

5.73

BMNH 3747

1.09

8.57

MCZ

8879

7.39

MNHN 1903.2

6.12

MNHN

QU 11058

11.95

MNHN

QU 11060

8.31

MNHN

QU 17285

10.41

MNHN

QU 17286

17.15

\section{Anaptomorphinae}

Absarokius noctivagus

USNM 22267

0.31

6.46

Shoshonius cooperi

CM

60493

0.39

8.45

CM

60494

0.28

8.15

Tetonius homunculus

$\begin{array}{ll}\text { AMNH } & 4204 \\ \text { USNM } & \text { DM2-61 }\end{array}$

0.46

8.21

USNM DM2-61

0.39

8.52

Incertae sedis

Rooneyia viejaensis

TMM

406887

0.96

18.99

\section{Plesiadapiformes}

\section{Carpolestidae}


Carpolestes dubius

$$
\text { AMNH } 97266
$$

0.92

Carpolestes nigridens

YPM

PU 14077

0.92

CM

70063

0.54

4.43

Micromomyidae

Tinimomys tribos

$\mathrm{CM}$

69337

0.61

1.53

Microsyopidae

Megadelphus lundeluisi

AMNH 55284

5.52

36.42

Microsyops latidens

YPM

23158

1.27

14.85

Microsyops sp.

CM

44449

20.75

Palaechthonidae

Palaechthon alticuspus

$\begin{array}{llll}\text { AMNH } & 35472 & 0.91 & 5.45 \\ \text { AMNH } & 35474 & 1.28 & 7.06\end{array}$

Paromomyidae

Ignacius graybullianus

UM

65569

3.98

5.39

USNM 421608

2.09

4.37

Paromomys maturus

AMNH 80993

1.82

9.48

USNM 9540

2.08

12.41

USNM 9541

1.99

10.97

Phenacolemur pagei

CM

71601

1.21

7.59

YPM

PU 14031

1.25

7.61

YPM

PU 14528

1.54

9.99

YPM

PU 16216

7.73

Plesiadapidae

Nannodectes gidleyi

$\begin{array}{llll}\text { AMNH } & 17171 & 1.49 & 13.62 \\ \text { AMNH } & 17173 & 1.19 & 13.59 \\ \text { YPM } & \text { PU 18791 } & 3.28 & 13.88 \\ \text { YPM } & \text { PU 19892 } & 1.01 & 19.26 \\ \text { YPM } & \text { PU 13393 } & 2.34 & 16.54 \\ \text { MNHN } & \text { CR-125 } & 4.46 & 36.91 \\ \text { MNHN } & \text { CR-126 } & 4.61 & 39.01 \\ \text { UM } & \text { Pellouin Skull } & 5.74 & 38.01\end{array}$

Plesiadapis churchilli

Plesiadapis dubius

Plesiadapis fodinatus

Plesiadapis tricuspidens

Pellouin Skull

1.59 


\section{Rodentia}

Tribosphenomys minutus

IVPP

17080c

0.25

1.13

Rhombomylus sp.

IVPP V5278

9.12

11.1

\section{Lagomorpha}

Dawsonolagus antiquus

IVPP $\quad$ V7462

1.22

3.81

The specimens used for this study are housed at the National Museum of Natural History (USNM,

Washington, D.C), the American Museum of Natural History (AMNH, New York, NY), the Carnegie Museum of Natural History (CM, Pittsburgh, PA), the Peabody Museum of Natural History (YPM, New Haven, Connecticut), the Harvard Museum of Comparative Zoology (MCZ, Cambridge, MA), the Museum of Paleontology at the University of Michigan (UM, Ann Arbor, MI), the Texas Vertebrate Paleontology Collections at The University of Texas at Austin (TMM, Austin, Texas), the British Museum of Natural History (BMNH, London, England), the Cambridge University Museum of Zoology (CMZ, Cambridge, England), the Muséum National d'Histoire Naturelle (MNHN, Paris, France), and the Naturhistorisches Museum Basel (NMB, Basel, Switzerland), Institute of Vertebrate Paleontology and Paleoanthropology (IVPP, Beijing, China).

IOF area and upper second molar area (MA) measurements were calculated as described in the Methods section. 
Table 2. Student's t-test comparing relative infraorbital foramen (IOF) area between major clades and orders. The top triangle are results obtained using conventional statistics. The bottom triangle represents the results of the phylogenetic t-test. To compare relative IOF sizes between taxa, residual IOF area was calculated for each species using a GLS or PGLS regression of $\ln$ IOF Area on $\ln$

Molar Area.

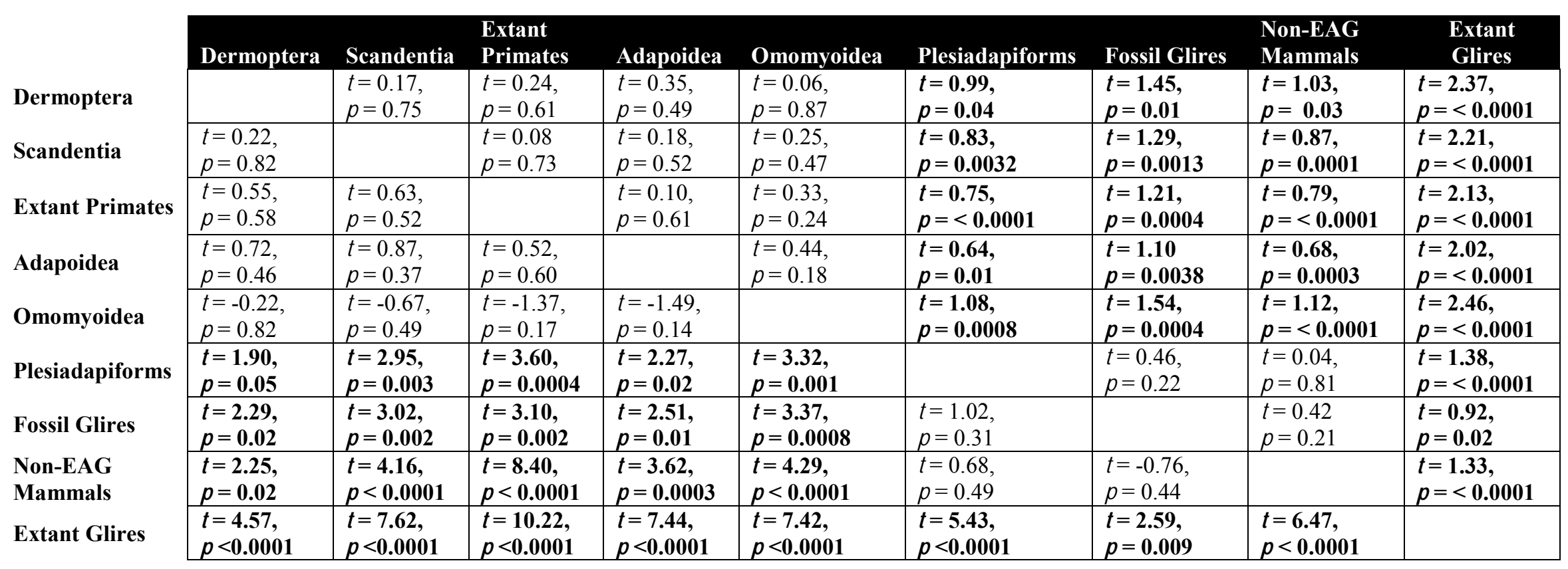

Values shown in bold font indicate differences that are statistically significant at $\mathrm{p}<0.05$.

$\mathrm{EAG}=$ euarchontoglires 